\title{
Prognosis and thallium-201 scintigraphy in patients admitted with chest pain without confirmed acute myocardial infarction
}

\author{
JAN KYST MADSEN, * MAX STUBGAARD, * HANS E UTNE, * \\ JØRGEN FISCHER HANSEN, * KOERT VAN DUIJVENDIJK, $\dagger$ \\ JOHAN H C REIBER, $\dagger$ KIRSTEN CHRISTOFFERSEN
}

From the Medical Department B and Department of Clinical Physiology, ${ }^{\star}$ Frederiksborg County Central Hospital in Hillerod, Denmark; the Department of Nuclear Cardiology, $\dagger$ Thoraxcentrum, Erasmus University and Academic Hospital Dijkzigt, The Netherlands; and Statistical Research Unit, $\ddagger$ University of Copenhagen, Denmark

SUMMARY Exercise and rest thallium scintigraphy and exercise electrocardiography were performed after discharge in 158 patients aged $<76$ years admitted with chest pain in whom a suspected diagnosis of acute myocardial infarction had not been confirmed. During a follow up of 12-24 months (median 14 months) there were 10 cardiac events-that is, non-fatal acute myocardial infarction or cardiac deaths. Transient thallium defects and abnormal ST response (that is ST segment deviation or uninterpretable ST segment) during exercise were correlated significantly with an unfavourable prognosis. One hundred and four patients with neither of these characteristics were at lower risk of a cardiac event than the 19 patients with both of these characteristics. The percentages of patients in these two groups without a cardiac event after one year were $98 \cdot 1$ and $78 \cdot 8$ respectively.

Thallium scintigraphy, alone or in combination with exercise electrocardiography, can be used to identify groups at high and low risk of future cardiac events, in patients with chest pain in whom acute myocardial infarction is suspected but not found.

Patients admitted with suspected acute myocardial infarction in whom the diagnosis is not confirmed have a high risk of cardiac events after discharge. ${ }^{1-3}$ The risk is almost as great as it is in patients discharged after a confirmed myocardial infarction. ${ }^{12}$ A method for identifying subgroups of high and low risk patients without acute myocardial infarction would be clinically useful. High risk patients could be considered for further investigations or close follow up, whereas low risk patients could be reassured about their prognosis.

Thallium scintigraphy at rest and during exercise is a sensitive and specific predictor of ischaemic heart disease. ${ }^{45}$ It has been used to identify high risk

Requests for reprints to Dr Jan Kyst Madsen, Medical Department B, Rigshospitalet, University Hospital, Blegdamsvej 9, DK-2100 Copenhagen, Denmark.

Accepted for publication $1 \mathrm{June} 1987$ groups in patients with chest pain, ${ }^{67}$ and in patients with recent acute myocardial infarction. ${ }^{89}$ The purpose of this prospective study was to evaluate whether thallium scintigraphy alone or in combination with exercise electrocardiography could identify high and low risk groups of patients admitted with chest pain without confirmed myocardial infarction.

\section{Patients and methods}

One hundred and fifty eight patients admitted with suspected acute myocardial infarction in whom this diagnosis was not confirmed were examined by exercise and rest thallium scintigraphy and exercise electrocardiography. Figure 1 shows that in a one year period (November 11981 to October 31 1982) 975 patients, residents of Frederiksborg County, Denmark, were admitted at least once with a suspected acute myocardial infarction to one of the four 


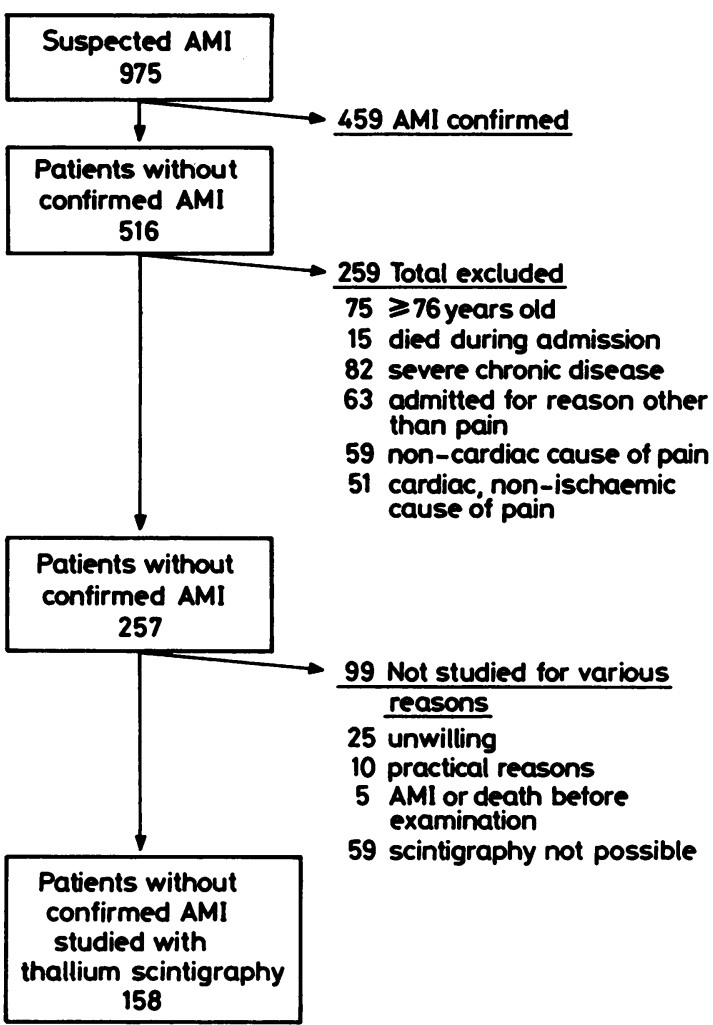

Fig 1 Flow chart showing patients admitted with chest pain, without confirmed acute myocardial infarction who were assessed by thallium scintigraphy and exercise electrocardiography.

coronary care units in the county. The suspicion of acute myocardial infarction was raised by the registrar on duty or by a general practitioner. Acute myocardial infarction was suspected if the patient had one or more of the following complaints: pain (that is, pain, pressure, or discomfort in chest, arms, or jaw for at least 20 minutes), severe dyspnoea, pulmonary oedema, cardiac arrest, electrocardiographic changes indicative of acute myocardial infarction, or syncope.

Acute myocardial infarction was confirmed in 459 patients (fig 1) who fulfilled at least one of the following three criteria: $(a)$ an increase in cardiac enzymes (that is lactate dehydrogenase $>8.34 \mu \mathrm{kat} / \mathrm{l}$; normal upper limit $7.09 \mu \mathrm{kat} / \mathrm{l}$ and/or aspartate aminotransferase $>0.83 \mu \mathrm{kat} / \mathrm{l}$; normal upper limit $0.67 \mu \mathrm{kat} / \mathrm{l}$ ); (b) electrocardiographic changes with development of $Q$ wave or ST-T displacement or $T$ wave inversion lasting $>48$ hours; (c) positive evidence of acute myocardial infarction at necropsy. If none of the above laboratory criteria were fulfilled acute myocardial infarction was not confirmed. Of the 516 patients without confirmed acute myocardial infarction, 259 were excluded because of one or more of the following exclusion criteria (fig 1): (a) age > 75 years at admission; (b) death during admission; (c) severe chroñic disease other than ischaemic heart disease (cancer, chronic pulmonary disease, sequelae of stroke, disability preventing investigations, for example arthritis); $(d)$ admission for reasons other than pain; $(e)$ confirmed non-cardiac aetiology of chest pain, for example pulmonary embolism, pleuro-pneumonia, ulcer, musculoskeletal pain; $(f)$ important non-ischaemic heart disease, for example valvar heart disease, pericarditis, cardiomyopathy, arrhythmias. Ninety nine patients were not examined for various reasons (fig 1), including 59 patients in whom thallium scintigraphy was not possible because time for examination on the gamma-camera was limited, problems with delivery of thallium, or technical difficulties during the study.

Thus finally 158 patients who had been admitted with chest pain had thallium scintigraphy and an exercise test. The study was accepted by the regional ethics committee. Thirty eight $(24 \%)$ of the patients were women and their median age was $56 \cdot 7$ years (range 32-75 years). Fifty nine patients had a history of angina pectoris and 34 of previous acute myocardial infarction.

Exercise electrocardiography combined with thallium scintigraphy was performed on the day of discharge or within four weeks of discharge. Exercise electrocardiography was performed three hours after the morning meal; the participants had not smoked or taken glyceryl trinitrate in this period. After 10 minutes of supine rest a 12 lead electrocardiogram was recorded. During exercise, leads V2, V4, and V6 were continuously recorded on paper at $10 \mathrm{~mm} / \mathrm{s}$ and every minute at $50 \mathrm{~mm} / \mathrm{s}$ for at least $15 \mathrm{~s}$.

A symptom limited exercise test was performed on an electrically braked ergometer. The initial workload was $50 \mathrm{~W}$ except in a few patients where it was $25 \mathrm{~W}$. The workload was increased by 50 (or 25) W every three minutes until the patient had to stop. ST segment changes during exercise were coded as: (a) normal; (b) ST deviation-that is elevation above $0.1 \mathrm{mV}$; ST depression at $\mathrm{J}$ point with horizontal or downsloping ST segment of $0.1 \mathrm{mV}$ or more; and (c) uninterpretable-that is left bundle branch block at rest or development of left or right bundle branch block during exercise; ST segment depression combined with either depression at rest, left ventricular hypertrophy, right bundle branch block, left hemiblock, or digoxin treatment. An abnormal exercise electrocardiogram was 
defined as ST segment deviation $(b)$ or uninterpretable (c).

Thallium chloride $(2 \mathrm{mCi})$ was injected intravenously one minute before the patients stopped exercising. Imaging was performed 5-10 minutes after the end of exercise and repeated after four hours.

Three images were acquired in $64 \times 64$ matrices with a GE Maxicamera large field of view: these were in anterior and left anterior oblique projections at $45^{\circ}$ and $65^{\circ}$. A zoom factor of 1.4 was used and 350000 counts were registered in the matrices. The total radiation exposure was approximately $140 \mathrm{mrad}$. The scintigrams were processed on a DEC gamma-11 system by a quantification procedure developed at the Thoraxcenter. ${ }^{10}$ The orientation of the redistribution images was adjusted for rotation and translation with respect to the corresponding exercise images by interaction with the computer system until the same orientations were obtained visually. After automated left ventricular contour detection and interpolative background subtraction, circumferential profiles were computed at $6^{\circ}$ intervals. The profiles of the exercise and redistribution images were normalised for the maximal value in the immediate post-exercise images $(100 \%)$ excluding the outflow tract of the left ventricle. The analogue pictures from the gamma camera, the processed images, and the circumferential profiles were analysed by three independent observers without knowledge of the clinical or exercise electrocardiographic data. The interpretations of the three observers were compared and disagreement was resolved by consensus.

The thallium uptake in a total of nine segments in the three views was scored as normal or abnormal in the immediate post-exercise and redistribution images. The following segments were defined: posteroinferior, apical, and anterior in the anterior view; anteroseptal, apical, and posterolateral in the left anterior oblique $45^{\circ}$ view; and anterior, apical, and inferoposterior in the left anterior oblique $65^{\circ}$ view. The scintigrams were considered to show: $(a)$ persistent defects if one or more segments showed abnormal areas without redistribution, (b) transient defects if one or more areas were initially abnormal, but later showed redistribution, or (c) normal uptake if both images were normal in all three views. The total number of permanent or transient defects and the locations were also calculated.

\section{FOLLOW UP}

The patients were followed from 12 to 24 months (median 14 months). Information on death was complete. It was obtained from the National Person Registration Office; in these cases further informa- tion was obtained from hospital records or death $C$ certificates. Information about acute myocardial $\vec{F}$ infarction was obtained from the County Central ${ }^{\rho}$ Registry, which contains information on all hospital등 admissions in the county. To cover the possibility of $\frac{\bar{c}}{\bar{c}}$. patients suffering an acute myocardial infarction $\bar{\Phi}_{\overparen{D}}$ outside the county all patients were sent one ques- $\frac{\circ}{0}$ tionnaire and one reminder. Ninety five per cent $\mathrm{c}$ answered the questionnaire. All recorded acute $\vec{\circ}$ myocardial infarctions occurred in the county.

STATISTICAL ANALYSIS

In the failure-time analysis a cardiac event was used as the end point. Non-cardiac deaths were excluded 0 and only the first appearance of a cardiac event was. considered. The probability of a cardiac event-free ${ }_{\perp}^{\infty}$ period after discharge was estimated by the Kaplan- 0 Meier method, corrected for possible delayed. entry. ${ }^{1112}$ The patients were considered to be at risk from the time of investigation until a cardiac evento or censoring (or from time of discharge if the investigation was performed before discharge). The estimated cardiac event-free curves for groups were $\vec{\oplus}$ compared by the log-rank test. ${ }^{12}$

\section{Results}

FOLLOW UP

During follow up there were 10 cardiac events in the patients in whom exercise electrocardiography and $\stackrel{\varrho}{a}$ thallium scintigraphy were performed. These were을 eight non-fatal acute myocardial infarctions, one fatal acute myocardial infarction, and one sudden death. Five events occurred within three months.

Eight cardiac events occurred in the 59 patients scheduled for thallium scintigraphy in whom the procedure could not be performed for reasons men-응 tioned earlier (fig 1). The prognosis for thesepatients was slightly worse than it was in the 158 ? patients in whom thallium scintigraphy was performed $(p<0.05)$.

THALLIUM SCINTIGRAPHY

Thallium scintigraphy was normal in $97(61.4 \%)$ N patients. Persistent defects were found in 48 N $(30.3 \%)$ patients; the location was anterior in seven posterolateral in 35 , both in four, and apical only in $\omega$ two patients. Transient defects were recorded in $29^{\circ}$ $(18.3 \%)$ patients; the location was anterior in six posterior in 14, and both in nine patients. Sixteen $(10 \cdot 1 \%)$ patients had both transient and persistent defects; 61 patients $(38 \cdot 6 \%)$ had either or both.

The table shows the prognosis in relation to thal $\frac{\mathrm{O}}{\mathrm{D}}$ lium scintigraphy. A transient defect was a very sensitive predictor of later cardiac events (fig 2) $\rho$ whereas persistent defects were not. An abnorma? 
Table Results of thallium scintigraphy and exercise electrocardiography and later cardiac events

\begin{tabular}{|c|c|c|c|c|}
\hline & $\begin{array}{l}\text { Total } \\
\text { No }\end{array}$ & $\begin{array}{l}\text { No with } \\
C E^{\star}\end{array}$ & $\begin{array}{l}1 \text { year \% } \\
\text { without a CE† }\end{array}$ & $p \|$ \\
\hline All patients & 158 & 10 & - & - \\
\hline \multicolumn{5}{|c|}{ Thallium scintigraphy } \\
\hline $\begin{array}{l}\text { Persistent defects: } \\
\text { No } \\
\text { Yes }\end{array}$ & $\begin{array}{r}110 \\
48\end{array}$ & $\begin{array}{l}6 \\
4\end{array}$ & $\begin{array}{l}93 \cdot 8 \\
94 \cdot 4\end{array}$ & 0.506 \\
\hline $\begin{array}{l}\text { Transient defects: } \\
\text { No } \\
\text { Yes }\end{array}$ & $\begin{array}{r}129 \\
29\end{array}$ & $\begin{array}{l}4 \\
6\end{array}$ & $\begin{array}{l}97 \cdot 8 \\
82 \cdot 6\end{array}$ & -0.001 \\
\hline $\begin{array}{l}\text { Combined: } \\
\text { No defect } \\
\text { Transient only } \\
\text { Persistent only } \\
\text { Both }\end{array}$ & $\begin{array}{l}97 \\
13 \\
32 \\
16\end{array}$ & $\begin{array}{l}2 \\
4 \\
2 \\
2\end{array}$ & $\begin{array}{l}97 \cdot 8 \\
69 \cdot 2 \\
93 \cdot 8 \\
93 \cdot 8\end{array}$ & 0.001 \\
\hline $\begin{array}{l}\text { Transient, persistent } \\
\text { defect, or both }\end{array}$ & 61 & 8 & $88 \cdot 5$ & $0.005 \ddagger$ \\
\hline \multicolumn{5}{|c|}{ Exercise electrocardiography } \\
\hline $\begin{array}{l}\text { Normal } \\
\text { ST deviation } \\
\text { Uninterpretable } \\
\text { ST deviation or }\end{array}$ & $\begin{array}{r}114 \\
20 \\
24\end{array}$ & $\begin{array}{l}3 \\
3 \\
4\end{array}$ & $\begin{array}{l}97 \cdot 3 \\
84 \cdot 5 \\
87 \cdot 5\end{array}$ & 0.005 \\
\hline uninterpretable & 44 & 7 & $86 \cdot 1$ & $0.001 \S$ \\
\hline $\begin{array}{l}\text { Thallium scintigraphy } \\
\text { Both tests normal } \\
\text { Either test abnormal } \\
\text { Both tests abnormal }\end{array}$ & $\begin{array}{l}\text { and exe } \\
104 \\
35 \\
19\end{array}$ & $\begin{array}{c}\text { cise electro } \\
2 \\
3 \\
5\end{array}$ & $\left.\begin{array}{l}\text { ardiography com } \\
98 \cdot 1 \\
90.9 \\
78.8\end{array}\right\}$ & $\left\{\begin{array}{l}\text { bined }^{\star \star} \\
0.001\end{array}\right.$ \\
\hline $\begin{array}{l}\text { *CE, cardiac event. } \\
\text { †Kaplan-Meier estim } \\
\text { after one year follow } \\
\text { tcompared with "no } \\
\text { \&compared with "norn } \\
\text { \|Log-rank test for con } \\
\text { follow up period. } \\
\star \star \text { Abnormal exercise } \\
\text { ST segment. }\end{array}$ & $\begin{array}{l}\text { of per } \\
\text { fect"; } \\
\text { l exerc } \\
\text { arison } \\
\text { st inclu }\end{array}$ & $\begin{array}{l}\text { entage } w \\
\text { e electro } \\
\text { f surviv } \\
\text { es ST d }\end{array}$ & $\begin{array}{l}\text { out a cardiac e } \\
\text { uriogram". } \\
\text { urves during th }\end{array}$ & $\begin{array}{l}\text { ent } \\
\text { e whole }\end{array}$ \\
\hline
\end{tabular}

scintigram, that is one showing transient, persistent, or combined defects, identified eight out of 10 patients with later cardiac events. Neither the number of areas with scintigraphic abnormalities nor their location gave further prognostic information.

\section{EXERCISE ELECTROCARDIOGRAPHY}

The exercise electrocardiogram was normal in 114 patients. ST deviation was seen in 20 patients. Four patients had ST elevation, 11 had $0 \cdot 1-0.2 \mathrm{mV}$ ST depression, and five patients had ST depression of $\geqslant 0.2 \mathrm{mV}$. The exercise electrocardiogram was uninterpretable in 24 patients (see Patients and Methods). The table shows the prognosis in relation to exercise electrocardiography.

\section{THALLIUM SCINTIGRAPHY AND EXERCISE \\ ELECTROCARDIOGRAPHY}

Cardiac events subsequently occurred in two of the $104(65.8 \%)$ patients with normal scintigraphythat is no transient defect and a normal exercise electrocardiogram. In $35(22.2 \%)$ patients either the exercise electrocardiogram was abnormal or thallium scintigraphy showed a transient defect. Three

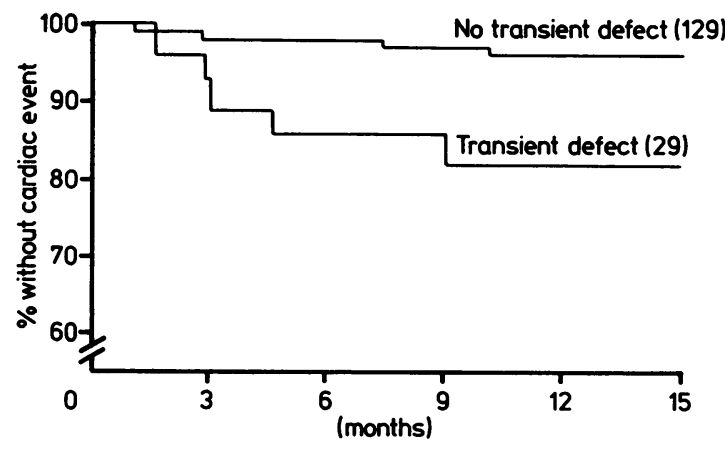

Fig 2 Kaplan-Meier estimates of percentage without a cardiac event in patients with transient defects or without transient defects on thallium scintigraphy.

of these patients later suffered a cardiac event. In 19 $(12.0 \%)$ patients both tests were abnormal-the exercise electrocardiogram showed ST deviation or was uninterpretable and thallium scintigraphy showed a transient defect. Five of these later suffered a cardiac event. Figure 3 shows the estimated percentage without a cardiac event over time. Patients in whom both tests were abnormal had a significantly worse prognosis.

\section{Discussion}

Patients admitted with suspected acute myocardial infarction because of chest pain in whom the diagnosis is not subsequently confirmed have a high risk of cardiac events after discharge. ${ }^{1-3}$ In the present groups the prognosis was only slightly better in the

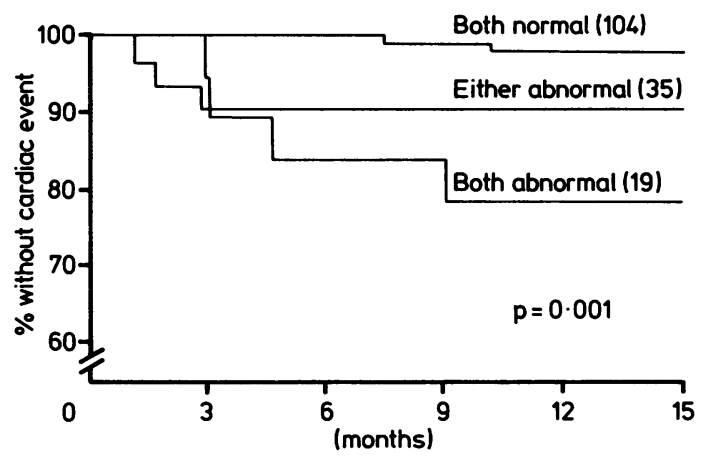

Fig 3 Kaplan-Meier estimates of percentage without a cardiac event in relation to the combination of exercise electrocardiography and thallium scintigraphy. Abnormal exercise electrocardiography includes $S T$ deviation or uninterpretable ST segment. Abnormal thallium scintigraphy includes transient defects only. Both normal, $n=104$; either abnormal, $n=35$; both abnormal, $n=19(p=0.001)$. 
257 patients without confirmed acute myocardial infarction (fig 1 ) than it was in a corresponding group of 275 patients discharged after confirmed acute myocardial infarction $(p=0.05) .{ }^{13}$ The estimated risk of cardiac events after one year was $8.7 \%$ and $13.9 \%$ respectively.

The purpose of this study was to see whether it was possible to identify different risk groups of patients without confirmed acute myocardial infarction by thallium scintigraphy alone or in combination with exercise electrocardiography. The presence of transient defects on thallium scintigraphy was significantly associated with later cardiac events (fig 2). Although the combination of permanent and transient defects identified eight out of 10 patients with cardiac events in the observation period, scintigraphy alone was not a specific indicator of prognosis, because permanent defects on their own were not related to prognosis.

These results accord with previous studies that have shown that thallium scintigraphy gives prognostic information on patients evaluated for chest pain. ${ }^{67}$ Iskandrian et al showed that the number of defects, transient or permanent, and the presence of perfusion defects were the two most important independent predictors of cardiac events in such patients. $^{7}$

Patients with chest pain and normal thallium scintigraphy have a good prognosis. ${ }^{1415}$ Pamelia et al found a cardiac event rate of $1.1 \%$ per year in such patients. ${ }^{14}$ The present study shows almost the same results. The incidence of cardiac events after one year was only $2 \cdot 2 \%$ (table 1 ). These results are also supported by the findings of Ilsley et al and Patterson et al, who found that in patients with chest pain important coronary artery disease can be ruled out with more than $90 \%$ certainty if both an exercise test and thallium scintigraphy are normal. ${ }^{16} 17$

The prognosis in patients in whom thallium scintigraphy was not possible was slightly worse than that in patients in whom it was performed. The selection of patients for scintigraphy was determined randomly by factors independent of the study. Thus the difference in prognosis must have occurred by chance.

ST segment depression during exercise was associated with an unfavourable prognosis, and a normal ST segment was associated with a good prognosis (table). This accords with studies of patients with angina pectoris. ${ }^{18}$ The ST segment response during exercise was uninterpretable in $15 \%$ of the patients (table). These patients too had a less favourable prognosis. When patients with an uninterpretable exercise electrocardiogram were grouped with patients with ST segment depression during exercise-that is an abnormal exercise electrocardiogram-the prognostic informationf. given by the exercise electrocardiogram and in thallium scintigraphy (table) is slightly different and in this study thallium scintigraphy gives the bes differentiation between groups.

A combination of the two methods gave the most information about prognosis (fig 3). The patients? could be divided into three groups according to thes event free rate after one year: (a) a low risk group $\vec{b}$ with two normal tests, making up two thirds of the total group, where $98.8 \%$ were event free; (b) a highw risk group with two abnormal tests, $12 \%$ of albू patients, of whom $78.8 \%$ were event free; (c) a medium risk group, making up one fifth of the population, with one abnormal test only in whom $90.8 \%$ were event free. Differences between risk $k_{p}^{\circ}$ groups did not become apparent until 3-6 monthso after assessment.

The study design meant that we studied youngerT patients with chest pain and without severe disease other than possible coronary heart disease. Never theless, the results show that both exercise electro cardiography and thallium scintigraphy can identify $\overrightarrow{0}$ high and low risk groups. The combination of the methods adds further prognostic information. Most patients are at low risk and such patients can be reas sured about the probable benign nature of theire chest pain and can be discharged without the neeou for outpatient follow up or further investigations $\frac{}{\circ}$ Patients with a high risk should be followed closely after discharge.

We thank the medical departments in Frederiks sund, Helsingør, and Hørsholm County Hospitals for referring their patients.

This study was supported by grants from the Danish Heart Foundation, the Danish Medica Research Council, The Foundation for Medicaf. Research of Bornholm, Frederiksborg, Roskilde? Storstrøm, and Vestsjælland Counties, and The Bryde Nielsen Foundation.

\section{References}

1 Madsen JK, Hansen JF. The prognosis for patiento admitted to a coronary care unit due to suspecteक् acute myocardial infarction with and withouf confirmed diagnosis. Acta Med Scand 1982 211:453-7.

2 Schroeder JS, Lamb IM, Hu M. Do patients in whomD myocardial infarction has been ruled out have $a^{+}$ better prognosis after hospitalisation than thosed surviving infarction? N Engl J Med 1980;301:1-5.

3 Nordlander $R$, Nyquist $O$. Patients treated in a coro nary care unit without acute myocardial infarction $\frac{\mathbb{D}}{\mathbb{D}}$ Identification of high risk subgroup for subsequen $\frac{}{0}$ myocardial infarction and/or cardiovascular death 
Br Heart $J$ 1979;41:647-53.

4 Ritchie JK, Zaret BL, Strauss HW, et al. Myocardial imaging with thallium-201: a multicenter study in patients with angina pectoris or acute myocardial infarction. Am J Cardiol 1978;42:345-50.

5 Bodenheimer MB, Banka VS, Fooshee CM, Helfant RH. Extent and severity of coronary heart disease. Determinations by thallous chloride T1 201 myocardial perfusion scanning and comparison with stress electrocardiography. Arch Intern Med 1979; 139:630-4.

6 Brown TE, Boucher CA, Okada RD, et al. Prognostic value of exercise thallium-201 imaging in patients presenting for evaluation of chest pain. J Am Coll Cardiol 1983;1:994-1001.

7 Iskandrian AS, Hakki A-H, Kane-Marsch S. Prognostic implications of exercise thallium-201 scintigraphy in patients with suspected or known coronary artery disease. Am Heart J 1985;110:135-43.

8 Perez-Gonzales J, Botvinick EH, Dunn R, et al. The late prognostic value of acute scintigraphic measurement of myocardial infarction size. Circulation 1982;68:960-71.

9 Gibson RS, Watson DD, Craddock GB, et al. Prediction of cardiac events after uncomplicated myocardial infarction: a prospective study comparing predischarge exercise thallium-201 scintigraphy and coronary angiography. Circulation 1983;68:321-36.

10 Reiber JHC, Lie SP, Simoons ML, Wijns W, Gerbrands JJ. Computer quantitation location, extent and type of thallium-210 myocardial perfusion abnormalities. In: Proceedings of the 1st International Symposium on Medical Imaging and Image
Interpretation ISMIII. Institute of Electrical and Electronics Engineers 1982; Cat No 82 CH1804-4: 123-8.

11 Gill RD. Censoring and stochastic integrals. Amsterdam: Mathematical Centre Tracts, 1980:124.

12 Mantel N. Evaluation of survival data and two new rank order statistics arising in its consideration. Cancer Chemotherapy Reports 1966;50:163-70.

13 Madsen JK, Thomsen BL, Sørensen JN, Kjeldgaard KM, Kromann-Andersen B. Risk factors and prognosis following discharge for patients admitted because of suspected acute myocardial infarction with and without confirmed diagnosis. Am J Cardiol 1987;59:1068-70.

14 Pamelia FX, Gibson RS, Watson DD, Craddock GB, Sirowatha J, Beller GA. Prognosis with chest pain and normal thallium-201 exercise scintigrams. Am J Cardiol 1985;55:920-6.

15 Wackers FJ, Russo DJ, Russo D, Clements JP. Prognostic significance of normal quantitative planar thallium-201 stress scintigraphy in patients with chest pain. J Am Coll Cardiol 1985;6:27-30.

16 Ilsley C, Stockley A, Clitsakis D, Layton C. Normal coronary arteriogram. An avoidable test? $\mathrm{Br}$ Heart $\mathrm{J}$ 1982;48:580-3.

17 Patterson RE, Horowitz SF, Eng C. Can exercise electrocardiography and thallium-201 myocardial imaging exclude the diagnosis of coronary artery disease. Am J Cardiol 1982;49:1127-35.

18 Weiner DA, Ryan TJ, McCabe CH, et al. Prognostic importance of a clinical profile and exercise test in medically treated patients with coronary artery disease. J Am Coll Cardiol 1984;3:772-3. 